\title{
Environmental Attitudes and Behaviors among Secondary Students in Hong Kong
}

\begin{abstract}
Although researchers have identified correlations between specific attitudes and particular behaviors in the pro-environmental domain, the general relationship between young people's development of environmental knowledge, attitudes, and behaviors is not well understood. Past research indicates that geographic context can play a role, while social factors such as age and gender can have a more significant impact on predicting attitudes and behaviors than formal education. Few studies have systematically examined the relationships between education and environmental attitudes and behaviors among youth in Hong Kong. This article reports the findings of a study comparing secondary school students' environmental attitudes and behaviors with age and related factors in 2 international schools and 2 government schools in Hong Kong. Students' attitudes and behaviors were compared based on school type (curriculum), while we additionally compared the significance of social factors and attitudes on students' behaviors. Attitudes were measured using the New Ecological Paradigm (NEP) and the NEP for Children (NEPC), the most commonly used, internationally standardized tools for investigating environmental attitudes and values of adults and young people for comparative purposes. We compared NEP/NEPC scores and student self-reported environmental behaviors using a short questionnaire. No significant differences were found in attitudes or behaviors based on school type. However we did observe a significant effect of gender and age on students' attitudes, and a significant correlation of student attitudes in the NEP with students' self-reports regarding air conditioning consumption. This study builds a foundation for cross-national studies and for evaluating the impact of curricula over time.
\end{abstract}

Keywords: Environmental education, environmental behavior, education for sustainable development, student attitudes, Hong Kong

\section{Introduction}

Historically associated with environmental education, education for sustainable development (ESD) aims ideally to not merely teach students abstract content knowledge about the environment, but to help also students understand how their behaviors and attitudes could have an impact on environmental sustainability (e.g., IUCN, 1970; UNCED, 1992). Because human attitudes and behaviors interrelate with social and cultural values and perceptions of moral and civic responsibilities, ESD today often emphasizes environmental conservation as well as the importance of individual and community participation in supporting the flourishing of communities from economic, cultural, and political perspectives (Barraza, Duque-Aristiza'Bal \& Rebolledo, 2003; Stevenson, 2006; Zhou, 2013). However, the relationship between individuals' attitudes and behaviors is not altogether clear in the research literature. Some contend that attitudes and beliefs actually play a more minor role than many believe in shaping peoples' behaviors (Arbuthnott, 2009; Subramanian, Abdulrahman, Wu \& Nath, 2015; Tan \& Lau, 2010), while others observe that geographic context and social factors such as gender can also play significant roles (Boeve-de Pauw, Donche \& Van Petegem, 2011; Goldsmith, Feygina \& Jost, 2012; Hunter, Hatch \& Johnson, 2004; Zelezny, Chua \& Aldrich, 2000). 
Very few studies have examined young people's attitudes or behaviors in recent years in Hong Kong. However many steps have been taken to integrate environmental education and education for sustainable development into Hong Kong curriculum to build students' knowledge and attitudes in the last few decades (Lee, Lam \& Williams, 2009; Luo, Lee \& Qiu, 2014). A recently (2009) introduced curriculum in Hong Kong local schools, Liberal Studies, increases focus on environmental sustainability issues. Though preliminary studies suggest that students perceive this new subject to have an impact on their environmental knowledge and behaviors (Zhu, Douglas \& Savelyeva, 2014), no research has compared students' attitudes with their behaviors in the environmental domain in Hong Kong, and little is known about how social factors such as gender and education impact Hong Kong students' attitudes or behaviors.

This article reports the findings of a study to examine how different educational curricula correlate with young people's attitudes and behaviors, and whether young people's attitudes and self-reported behaviors in the environmental domain are correlated within Hong Kong. To investigate the potential impact of curricula on Hong Kong youth, we compared secondary students' attitudes and self-reported behaviors across two local (government-curriculum) schools and two international (private-curriculum) schools in Hong Kong. To measure attitudes, we used the New Ecological Paradigm Scale (NEP) and the NEP for Children (NEPC), the most commonly used, international standardized tools for measuring environmental attitudes, in addition to a self-designed questionnaire about students' proenvironmental behavior. We sought to uncover through the analysis the respective predictive impacts of educational type (private or local/public) and other social factors such as age, nationality, and gender on students' attitudes and behaviors, as well as the relationship between students' attitudes and behaviors. Through shedding light on the relationship between education and attitudes and behaviors in Hong Kong, this study can help inform those hoping to increase education's impact on environmental attitudes and behaviors among young people in Hong Kong; it can also contribute to the larger research literature seeking to elucidate the relationship among people's environmental knowledge, attitudes, and behaviors in different geographic contexts more generally. The next section of this article gives an overview of the development of environmental education and education for sustainable development in Hong Kong, and discusses some of the findings related to the relationship between knowledge, attitudes, and behavior in previous research. This article then elaborates our study and its results in relation to enhancing the future impact of education for sustainable development in Hong Kong.

\section{Education for Sustainable Development in Hong Kong}

Though the history of environmental education and education for sustainable development in Hong Kong shows that much progress has been made in incorporating more interdisciplinary sustainability education into the curriculum over time, attitudinal surveys of the public and students in recent years and related investigations of the curriculum have suggested that further formal educational support is needed. The Hong Kong Education Bureau's Curriculum Development Council first created guidelines on environmental education in 1992, which were revised in 1999. Their aim was to create a cross-curricular approach to environmental education, wherein it would be incorporated into existing subjects (CDC, 1992, 1999), in line with conceptualizations of ESD as related not only to environmental conservation, but to social, economic, and political issues and development in the local context. However for many years after this reform Stimpson (1997) observed that, "incorporation across existing mainstream school subjects is generally not occurring...half the schools in total who replied were not intending to follow the recommendations of the guidelines” (p.352). Lee (1997) 
similarly found that schools were failing to incorporate environmental education into subjects, and that there was a fissure between what guidelines suggested, and what many schools were doing. In a later study, Lee elaborated disparities prevalent across local schools in Hong Kong, in "institutional commitment, school curriculum, teaching approaches and strategies, environmental education activities [and] environmental support and resources” (2000, p.95). Because environmental education was not more formally included in the curriculum as an independent subject, teachers and administrators were able to overlook it. In addition, the Hong Kong government school system uses a centralized public examination system, and teachers are widely understood to be under pressure to prepare students for tests to proceed academically. Thus, if a subject is not related to the test, teachers often overlook it (Stimpson, 1997; see also Leung, 2002; Leal Filho \& Behrens, 2003).

In relation, at the turn of the twenty-first century it was observed that the general public of Hong Kong (Lee, 2000) and secondary students (Yeung, 1998) expressed low levels of concern for the environment, and unwillingness to actively participate in environmental protection, according to polling. In the last decade many ESD school initiatives have been implemented with support and funding from the Educational Bureau of Hong Kong. However, these have been largely school-based and according to researchers their success or failure appears to be largely dependent upon the initiative, will, and/or strong support of key individuals within in-school management (Lee, Lam \& Williams, 2009; Luo, Lee \& Qiu, 2014; Tsang \& Lee, 2014).

A more promising educational reform occurred in 2009, when Hong Kong secondary school curriculum was revised to include a new required interdisciplinary subject, Senior Secondary Liberal Studies. This subject has six interdisciplinary modules focused on developing student skills and cross-curricular application of knowledge (CDC, 2009/2014). Independent studentled inquiry and other aspects emphasize a student-centered valuation and use of knowledge, in contrast with the traditionally teacher-centered educational approach historically seen in Hong Kong education, which has also been cited as an obstacle to making an impact on students environmental behaviors and attitudes (Lee, 2009; also Adamson \& Li, 2004). Sustainability has a clear role in this curriculum, as one of its six modules is "Energy Technology and the Environment.” As science education is not required for all students in senior secondary education (and in any case hardly focuses on social, political-economic or cultural issues related to sustainability and sustainable development), Liberal Studies is seen today as the key place for young people to learn about environmental sustainability in Hong Kong.

As the first cohorts of Liberal Studies-trained teachers are only now graduating from teacher education programs and taking places in Hong Kong local schools, to a significant extent Liberal Studies' impact remains to be seen. One recent study has indicated its preliminary perceived impact on knowledge and behavior among university students who studied Liberal Studies as secondary students; however, the research found that only 39\% of students reported gaining "more" or "much more knowledge" from Liberal Studies, while less than half reported that they perceived that their environmental behaviors had changed (Zhu, Douglas \& Savelyeva, 2014, p.12). On the other hand, Zhu and colleagues (2014) also found that many of the participants credited the media and non-formal education as significant additional influences, while many Hong Kong youth attend international (private) schools, offering Advanced Placement, International Baccalaureate, or other international curricula, that may include more focus on sustainability issues, given their global orientations. As there is little known about Hong Kong youths' environmental attitudes and behaviors in the contemporary context and how they may correlate with educational experiences and knowledge, it is 
worthwhile to compare the attitudes and behaviors of secondary students studying under different curricula in Hong Kong youth today, to evaluate potential curricular impacts, while building a foundation for comparative studies that are cross-national and can evaluate the impact of curricula on Hong Kong students over time.

Intuitively environmental educators seek to impact students' pro-environmental behaviors via enhancing their environmental knowledge, and in some environmental education research attitude is assumed to be a predictor of environmental behavior (Tan, 2011). As Sterling (2010) notes, "raising awareness and knowledge about environmental issues will, rationally and causally, lead to personal and behavioral change, and if followed in great enough numbers, to social change” (2010, p.513). Gottlieb, Vigoda-Gadot and Haim (2013) describe this approach as "Ecological Value Theory": "individuals who hold environmental values are highly likely to behave in an environmentally responsible way" (p. 850).

However in Gottlieb and colleagues' review (2013), they found a somewhat weak relationship between attitudes and behaviors. Increasingly, green competencies are conceived as highly specific to context (to particular attitudes or particular behaviors) and as interdependent with appropriate knowledge that pertains to the situation at hand and one's personal positionality. Yet, as Subramanian and colleagues note (2015), people with pro-environmental attitudes and concerns may not engage in predicted behaviors, because they do not necessarily see connections between their knowledge of productive change; their own well-being, their future well-being, and that of others; and their capacity to take action (see also Tan \& Lau, 2010). Thus, the knowledge of environmental impacts must interface with knowledge of one's own capacities in light of the complex scale of environmental challenges. In relation, geographical context matters; as Boeve-de Pauw, Donche, and Van Petegem (2011) found, youth from countries with many natural resources, and youth from countries with more environmental problems show higher environmental values than others (see also Liu \& Constable, 2010, p.271). As Arbuthnott (2009) argues, attitudes can be a predictor of behavior, but attitudes and intentions should not be preconceived as the sole or even primary predictor of behavior, given the importance of political, cultural, and other aspects of social context.

As discussed by Goldsmith and colleagues (2012), gender has been found to be among the most important factors in differences in people's environmental attitudes, knowledge, and behaviors across many countries, societies, and age groups. In an international study of public attitudes, women in nearly every country were more concerned with climate change harming people than men (World Bank, 2009), while a related study found that women from 20 societies were more likely to participate in pro-environmental behavior than men in the private sphere (Hunter, Hatch \& Johnson, 2004). Zelezny, Chua, and Aldrich (2000) found related correlations across age in 14 countries, with stronger impacts evident related to behavior than attitudes, which they saw as related to women having "higher levels of socialization to be other oriented and socially responsible” than men (p.443).

Our study is the first to provide a comparison of curriculum (international versus local) to self-reported environmental attitudes and behaviors among Hong Kong secondary schools students. In order to compare curriculum and other (interrelated) socialization impacts on environmental attitudes and behaviors, we also engaged in a comparison of attitudes and behaviors of participants by age, nationality, and gender.

\section{Methodology}

Our study uses a quantitative case study design to identify and analyze relationships between 
secondary school students' self-reported environmental attitudes and behaviors, and compare potential differences in self-reported attitudes and behaviors according to age, gender, nationality, and school type. Implicit in the design of the research is a grounded orientation to social science and educational research; we regard student self-reports as valid data sources for developing a broad understanding of their environmental attitudes and behaviors, even if such a research design cannot elaborate comprehensive portraits of individual students' conceptualizations of their environmental attitudes and behaviors, and despite the possibility that such an approach neglects to explore possible complexities between student self-reports and their observable behaviors, which other research methods might examine.

We administered questionnaires to secondary students at two international schools and two local schools in Hong Kong. A total of 483 students participated in the study. Student participants were aged from 11-19. Convenience sampling was used to identify secondary schools, to enable widespread participation within schools familiar to the research team. (The principal investigators for this research have no past or current affiliation with any schools analyzed.) Questionnaires were administered paper form or electronically using Google Docs, at the request or preference of in-school collaborators. Institutional research ethics approval was obtained prior to recruiting participants in schools, and all participants gave voluntary consent prior to taking the questionnaires. Similar procedures were used at all schools, with assistance and collaboration from teachers.

To measure student attitudes, we administered the New Ecological Paradigm (NEP) and New Ecological Paradigm for Children (NEPC) questionnaires. The NEP is the most commonly used measurement of its kind for measuring environmental attitudes and comparing them across groups and over time/treatment. Hawcroft and Milfont's (2010) meta-analysis revealed the NEP was statistically valid for measuring environmental attitudes when given to students aged 18. As more than $80 \%$ of research projects using the NEP employ a 5-point Likert scale, we used the 5-point scale here for consistency (Hawcroft \& Milfont, 2010). The NEPC is a variation of the NEP that was produced to better suit examinations of attitudes, and changes in attitudes, of children as young as 10 years old (Manoli, Johnson \& Dunlap, 2007; Bertling, 2012). The NEPC is composed of 10 questions instead of 15. Questions are still on a Likert scale, rated positively and negatively to avoid bias. Students older than 16 years old were given the NEP, while those under 16 years old were given the NEPC. As a supplement to the NEP/NEPC, to understand the relationship between students' attitudes and values and behaviors, our research team designed and administered (after piloting) a brief additional questionnaire. This questionnaire contained 14 questions about students' personal behaviors related to the environment, also on a 5-point Likert scale. As previous ESD research with young people has indicated that the particular environment (geographic context) and people's perceptions of it can play a role in their values and attitudes (Boeve-de Pauw, Donche \& Van Petegem, 2011), we also included questions about students' perceptions of the current environmental situation and future of Hong Kong within this supplementary questionnaire. To avoid language barriers during test administration, we used back-translation of the NEP, NEPC, and self-designed behaviors questionnaire, to offer the surveys in the most common locally used language, in this case traditional characters (Chinese). First a primary translator translated the questionnaire from English to Chinese, and then a second, unrelated translator translated it back to English (Lai, Brennan, Chan \& Tao, 2003).

Five surveys were excluded from data analysis as they indicated inconsistent answering patterns (e.g. “1” marked for every question). Results from 478 surveys (280 for NEP and 198 for NEPC) were therefore used for quantitative analysis. Data analysis was conducted using $\mathrm{R}$ 
(R Core Team, 2014). Multiple regression analysis was conducted to test which factors affect the NEP/NEPC scores. Factors tested included gender, type of school, age, and nationality. Spearman's rank order correlation tests were subsequently run to analyze correlations between NEP/NEPC scores (attitudes and values) and student responses to our independently-designed behaviors questionnaire.

\section{Results}

The mean NEP score across all surveys was 3.44. The mean NEPC score was 3.70.

\section{Influence of social factors on NEP}

NEP and NEPC score averages were fairly consistent across schools, with no observable trends based on the type of school (international or local) or nationality (Table 1). However, both NEP and NEPC scores varied significantly with gender (Table 1). Female students scored higher on both tests (NEP mean $=3.51$, NEPC mean $=3.85)$ than male students (NEP mean $=3.31$, NEPC mean $=3.53)$. There was also a significant effect of age on NEP scores, but no effect of age on NEPC scores.

Table 1 Results of a multiple linear regression analysis testing for correlations between social factors and NEP/NEPC scores.

\begin{tabular}{l|llllll}
\multicolumn{1}{c}{} & \multicolumn{3}{c}{ NEP } & \multicolumn{3}{c}{ NEPC } \\
& Coefficient & Error & $\mathrm{P}$ & Coefficient & Error & $\mathrm{P}$ \\
\hline Age & 0.04 & 0.02 & $0.04^{*}$ & 0.008 & 0.02 & 0.73 \\
Gender & 0.18 & 0.07 & $0.01^{*}$ & 0.18 & 0.06 & $0.008^{*}$ \\
School Type & 0.05 & 0.09 & 0.60 & -0.04 & 0.09 & 0.67 \\
Nationality & 0.0006 & 0.03 & 0.98 & -0.03 & 0.03 & 0.35
\end{tabular}

* Significance at the 0.05 level.

\section{Relationship between NEP and behavior}

From the results of our behavioral questionnaire, only one reported behavior correlated significantly with NEP scores (and none correlated significantly with NEPC scores). Responses to the statement "I leave the air conditioner on when I'm not at home" correlated significantly with the NEP scores $\left(r_{s}=-0.12, p=0.04, \mathrm{~N}=276\right)$, but not with NEPC scores $\left(r_{s}\right.$ $=-0.01, p=0.87, \mathrm{~N}=196)$. As NEP scores increase, students more frequently report turning off the air conditioner when not at home. This correlation is significant, although weak.

Two further behaviors showed a non-significant trend in relation to NEP/NEPC scores. Higher NEP and NEPC scores were associated with people who "almost always" recycle, but the effect was not significant (NEP: $r_{s}=0.07, p=0.26, \mathrm{~N}=279$; NEPC: $r_{s}=0.102, p=0.15$, $\mathrm{N}=197$ ). Higher scores on both questionnaires were also weakly associated with people who "never" throw out food when they cannot finish it (NEP: $r_{s}=-0.05, p=0.42, \mathrm{~N}=276$; NEPC: $\left.r_{s}=-0.07, p=0.35, \mathrm{~N}=196\right)$.

\section{Discussion}

To measure the efficacy of educational treatments on students' attitudes and behaviors within school types (international versus local), researchers can compare students within a school population by age or grade level. The NEP was created in part to measure such changes within an educational setting, and in past research using the NEP in other contexts it has demonstrated the efficacy of some educational interventions on impacting individuals' attitudes (Hawcroft \& Milfont, 2010). Our small-scale study indeed revealed significant differences between students' attitudes and values within schools as reported in the NEP 
based on age. This suggests that educational experiences may have an impact on students aged 16-19. However, correlation need not imply causation, as a recent study by Zhu and colleagues (2014) also identified the perceived influence of non-formal educational sources (including television, the Internet, and newspapers) on young people's environmental attitudes in Hong Kong. Students in Hong Kong may be learning through formal curriculum environmental knowledge that changes their attitudes; however more research is needed to confirm this possibility, as age need not reflect educational differences but may also reflect other socialization or individual developmental factors.

Previous research has suggested that given Hong Kong local schools' historical lack of substantive curriculum for environmental education or education for sustainable development, the more globalized curriculum used in international schools might emphasize environmentalism more and have a bigger impact on young peoples' attitudes and behaviors. As seen here, Hong Kong society has historically had lower levels of pro-environmental attitudes than other societies according to polling of adults in recent decades (Lee, 2000), though a confounding factor here is cultural and national context, as culture and physical geography can also play a significant role in attitudes and behaviors (Boeve-de Pauw, Donche \& Van Petegem, 2011; Liu \& Constable, 2010, p.271). In any case, a significant difference in students' environmental attitudes or behaviors by school type would reflect different curricular foci of schools, or differences across schools' or students' cultural contexts, when comparing students by nationality. However, we found that school type (local or international) and students' nationality did not play major roles in students' environmental attitudes or behaviors, as scores were similar across the four schools (two international and two local). Due to the small sample size, further research should be conducted to confirm whether school type does not correlate with students' environmental attitudes in Hong Kong (and whether it is valid to regard international and local curricular contexts as different for education for sustainable development). If curriculum and school type (and nationality) has little impact on students' attitudes and behaviors while age and geographical context do (Boeve-de Pauw, Donche \& Van Petegem, 2011) this would strengthen support for the possibility that formal curriculum is less important than other socialization factors, including the nonformal educational context of public campaigns and the like, in shaping young peoples' environmental attitudes and behaviors.

In line with international research reports from many different societies around the world, we identified a significant relationship between gender and environmental attitudes as reported in both the NEP and the NEPC. However, no significant relationship between gender and environmental behaviors was identified, in contrast with other research findings from international studies (Hunter, Hatch \& Johnson, 2004; Zelezny, Chua \& Aldrich, 2000). Again, this correlation suggests the possible impact of non-formal or informal socialization experiences or "hidden curriculum" experiences (i.e., those experiences within and outside of formal education that are not part of the planned curriculum) on young people's development of environmental attitudes in Hong Kong (as elsewhere), given Zhu and colleagues' (2014) related findings about students' perceptions of the influence of non-formal education.

Little research to date has evaluated the relationship between environmental attitudes, local environmental perceptions, and behavior among Hong Kong students, though the relationship among these variables is contested in previous international research (Gottlieb, Vigoda-Gadot \& Haim, 2013; Tan \& Lau, 2010). There was no correlation found between student perceptions about the situation and/or future of Hong Kong and their environmental attitudes and values. However our data does shed light on a plausible relationship between student 
values and behaviors related to the environment. Our research suggests that for older students' (those who took the NEP; those 16 and older) environmental attitudes and values interact with student self-reported decreased use of air conditioning. This correlation was statistically significant, but still rather weak. Non-significant corrections were found between NEP attitude scores and recycling and food waste behaviors. Larger-scale research is essential to confirm whether such correlations might be common or typical across Hong Kong youth. As correlations between attitudes and behaviors were weak or non-significant in our study overall, this finding seems to echo past international research that suggests the relationship between attitudes and behaviors in the environmental domain is highly complex and is not simply or directly causal.

While our findings indicate that socialization factors, particularly age and gender, make a difference, which factors educators can influence to impact youths' attitudes and behaviors in Hong Kong remains unclear. Because the relationships between student attitudes, knowledge, and behaviors appears to be contextually specific and complex, more research to elaborate the socialization and educational context of Hong Kong youth, within and outside education, is critical to uncover further evidence regarding how young people can be impacted through sustainability education of different kinds. Further examination of contemporary curriculum for environmental and sustainability education in the formal and non-formal education sectors in Hong Kong (including the work of NGOs) can provide greater understanding of latent attitudes that underpin educational content. Personal relationships can be a related important factor within socialization, which appears to significantly impact attitudes and behaviors in some regards according to our findings. Thus, the relationship between teachers and students' attitudes and behaviors towards the environment can also be explored, as correlations between the two groups could justify enhancing teacher education and training programs in this area, for example. There may also be a significant relationship between students and parents' attitudes, as our research suggests that students' attitudes are positively correlated with at least one environmentally related behavior (air conditioning consumption) that happens in the home.

\section{Conclusion}

In environmental education research, the relationship between people's attitudes and their behaviors remains controversial. While some researchers positively correlate attitudes with behaviors, others argue that this relationship may be indirect, with behavior impacted more by other factors, including socialization related to age and gender. Related research also suggests that the attitudes and behaviors of youth depend significantly on geographic, national, and cultural context, such that a possible relationship between values and behaviors identified in one setting cannot be easily presumed valid for the purposes of enhancing education for sustainability in other settings. Meanwhile, past research has shown that in Hong Kong education for sustainable development has not been integrated into the curriculum effectively. However, to date no research has examined whether Hong Kong students' environmental knowledge, attitudes or behaviors are correlated, or whether other socialization factors such as gender, age, or nationality play significant roles. Additionally, since the introduction of Liberal Studies, no research has investigated the impact of the curriculum on students' environmental attitudes, or compared the environmental attitudes of local or international school students in Hong Kong.

This research project compared the environmental attitudes of secondary students in Hong Kong by age, gender, nationality, school type (local or international), and in relation to their self-reported behaviors and perceptions about Hong Kong. We found significant differences 
by age in the NEP and by gender in responses to both the NEP and NEPC, but we found no significant differences by school type, in our research, leaving unclear the question of whether formal education and curriculum are playing a major role in students' attitudes development, compared to outside socialization factors. We also found no major differences in student environmental attitudes related to their perceptions about Hong Kong. However, our research does suggest that students' environmental attitudes are related to some personal behaviors for Hong Kong secondary students. We found that students with more pro-environmental attitudes as found in the NEP are more likely to conserve air conditioning.

These findings suggest that socialization factors indeed make a difference for young peoples' environmental attitudes and behaviors in Hong Kong, as elsewhere according to international research studies. However to better understand this role in the particular context of Hong Kong, further research is needed to uncover the potential influences of curricula and educator and parental attitudes and behaviors, to better understand what factors can be changed and controlled by educators in order to enhance young people's attitudes and behaviors more effectively in the future.

\section{Acknowledgement}

The authors wish to thank [anonymized] and [anonymized] for assistance with translation. This research was funded by the [anonymized].

\section{References}

Adamson, B. and Li, S. P. T. (2004), "Primary and secondary schooling”, in Bray, M., and Koo, R. (Eds.), Education and Society in Hong Kong and Macao: Comparative Perspectives on Continuity and Change, University of Hong Kong Comparative Education Research Centre/Kluwer, Hong Kong, pp. 15-34.

Arbuthnott, K. D. (2009), “Education for sustainable development beyond attitude change”, Journal of Sustainability in Higher Education, Vol. 10 No. 2, pp. 152-163.

Barraza, L., Duque-Aristiza'Bal, A. and Rebolledo, G. (2003), "Environmental education: From policy to practice”, Environmental Education Research, Vol. 9 No. 3, pp. 347-357.

Bertling, J. G. (2012), "The art of empathy: A mixed method case study of a critical placebased art education program”, International Journal of Education and the Arts, Vol. 16, pp. 1-27.

Boeve-de Pauw, J., Donche, V. and Van Petegem, P. (2011), “Adolescents' environmental worldview and personality: An explorative study”, Journal of Environmental Psychology, Vol. 31, pp. 109-117.

Curriculum Development Council (CDC). (2009/2014), Guidelines on Senior Secondary Liberal Studies, Education Bureau, Hong Kong.

Curriculum Development Council (CDC). (1992/1999), Guidelines on Environmental Education in Schools, Education Bureau, Hong Kong.

Goldsmith, R. E., Feygina, I. and Jost, J. T. (2013), "The gender gap in environmental attitudes: A system justification perspective“, in Alston, M. and Whittenbury, K. (Eds.), Research, Action, and Policy: Addressing the Gendered Impacts of Climate Change, Springer, pp. 159-171.

Gottlieb, D., Vigoda-Gadot, E. and Haim, A. (2013), "Encouraging ecological behaviors among students by using the ecological footprint as an educational tool: A quasi- 
experimental design in a public high school in the city of Haifa", Environmental Education Research, Vol. 19 No. 6, pp. 844-863.

Hawcroft, L. J. and Milfont, T. L. (2010), "The use (and abuse) of the new environmental paradigm scale over the last 30 years: A meta-analysis”, Journal of Environmental Psychology, Vol. 30, pp. 143-158.

Hunter, L. M., Hatch, A. and Johnson, A. (2004), "Cross-national gender variation in environmental behaviors”, Social Science Quarterly, Vol. 85 No. 3, pp. 677-694.

International Union for the Conservation of Nature and Natural Resources (IUCN). (1970), Final report: International Working Meeting on Environmental Education in the School Curriculum, IUCN Gland, Switzerland.

Lai, C.-l. J., Brennan, A., Chan, H.-M. and Tao, J. (2003), “Disposition toward environmental hazards in Hong Kong Chinese: Validation of a Chinese version of the environmental appraisal inventory (EAI-C)”, Journal of Environmental Psychology, Vol. 23 No. 4, pp. 369-384.

Leal Filho, W. and Behrens, R. (2003), "Trends in education for sustainability”, in Hill P. and Man, C. S. (Eds.), New Directions in Environmental Education in Hong Kong, Centre of Urban Planning and Environmental Management, University of Hong Kong, Hong Kong, pp. 1-14.

Lee, J. C.-K. (1997), “Environmental education in schools in Hong Kong”, Environmental Education Research, Vol. 3 No. 3, pp. 359-371.

Lee, J. C.-K. (2000), “Teacher receptivity to curriculum change in the implementation stage: The case of environmental education in Hong Kong”, Journal of Curriculum Studies, Vol. 32 No. 1, pp. 95-115.

Lee, J. C.-K. (2009), “Green primary schools in Hong Kong”, in Lee, J. C.-K. and Williams, M. (Eds.), Schooling For Sustainable Development in Chinese communities: Experience with Younger Children, Springer, pp. 195-212.

Lee, J. C.-K., Lam, W.-P. and Williams, M. (2009), "The education for sustainable development project in Hong Kong”, in Lee, J. C.-K. and Williams, M. (Eds.), Schooling For Sustainable Development in Chinese communities: Experience with Younger Children, Springer, pp. 157-176.

Lee, J. C.-K., Williams, M. and Lam, W.-P. (2009), "Case studies from the education for sustainable development project in Hong Kong”, in Lee, J. C.-K. and Williams, M. (Eds.), Schooling For Sustainable Development in Chinese communities: Experience with Younger Children, Springer, pp. 177-194.

Leung, W.-M. V. (2002), A Study of the Implementation of Environmental Education in Hong Kong Secondary Schools, University of Hong Kong, Hong Kong [doctoral dissertation].

Liu, Y. and Constable, A. (2010), "ESD and lifelong learning: A case study of the Shangri-la Institute's current engagement with the Bazhu community in Diqing, China", International Review of Education, Vol. 56 No. 2, pp. 271-285.

Luo, J. M., Ngok, L. and Qiu, H. (2014), "Education for sustainable development in Hong Kong: A review of UNESCO Hong Kong's experimental schools”, Public Administration and Policy, Vol. 18, pp. 48-61. 
Manoli, C., Johnson, B. and Dunlap, R. E. (2007), “Assessing children's environmental worldviews: Modifying and validating the new ecological paradigm for use with children,” Journal of Environmental Education, Vol. 38, 3-13.

R Core Team (2014), R: A Language and Environment for Statistical Computing. R Foundation for Statistical Computing, Vienna, Austria.

Robertson, M. and Lee, J. C.-K. (2009), "Leading curriculum change for education for sustainable development in schools”, in Lee, J. C.-K. and Williams, M. (Eds.), Schooling For Sustainable Development in Chinese communities: Experience with Younger Children, Springer, pp. 95-114.

Sterling, S. (2010), "Learning for resilience, or the resilient learner? Towards a necessary reconciliation in a paradigm of sustainable education", Environmental Education Research, Research, Vol. 16, No. 5-6, pp. 511-528.

Stevenson, R. B. (2006), "Tensions and transitions in policy discourse: Recontextualizing a decontextualized EE/ESD debate”, Environmental Education Research, Vol. 12 No. 3-4, pp. 227-290.

Stimpson, P. G. (1997), "Environmental challenge and curricular responses in Hong Kong”, in Environmental Education Research, Vol. 3 No. 3, pp. 345-357.

Subramanian, N., Abdulrahman, M. D., Wu, L., \& Nath, P. (2015), "Green competence framework: evidence from China”, Journal of Human Resource Management [online first].

Tan, B. C. (2011), "The role of perceived consumer effectiveness on value-attitude-behavior model in green buying behavior context”, Australian Journal of Basic and Applied Sciences, Vol. 5, pp. 1766-1771.

Tan, B. C. and Lau, T. C. (2010), “Attitude towards the environment and green products: Consumers’ perspective”, Management Science and Engineering, Vol. 4, pp. 27-39.

Tsang, E. P.-K. and Lee, J. C.-K. (2014), "ESD projects, initiatives and research in Hong Kong and Mainland China”, in Lee, J. C.-K. and Efird, R. (Eds.), Schooling for Sustainable Development Across the Asia Pacific, Springer, pp. 203-221.

United Nations. (1993), Agenda 21: 'The United Nations Programme of Action from Rio, United Nations, New York.

United Nations Conference on Environment and Development (UNCED). (1992), Promoting Education, Public Awareness and Training: Agenda 21, UNCED, Rio de Janeiro.

World Bank. (2003), Country at a Glance, available at http://www.worldbank.org/data/countrydata/countrydata.html.

Yeung, S. P.-M. (1998), "Environmental consciousness among students in senior secondary schools: The case of Hong Kong”, Environmental Education Research, Vol. 4 No. 3, pp. 251-268.

Zelezny, L. C., Chua, P.-P. and Aldrich, C. (2000), "Elaborating on gender differences in environmentalism”, Journal of Social Issues, Vol. 56 No. 3, pp. 443-457.

Zhou, M. (2013), “A multidimensional analysis of public environmental concern in Canada”, Canadian Sociological Association, University of Victoria, Victoria. 
Zhu, J.-X., Douglas, W. and Savelyeva, T. (2014), Effects of Liberal Studies on Hong Kong Students' Environmental Knowledge and Behaviour. Hong Kong: Centre for Lifelong Learning Research and Development, The Hong Kong Institute of Education. 